\title{
Comparison of calculation models' estimates with actual measured autogenous shrinkage in High-Performance Cement Composites
}

\author{
Adam Zieliński ${ }^{1, *}$, Karol Federowicz ${ }^{1}$, and Maria Kaszyńska ${ }^{1}$ \\ ${ }^{1}$ West Pomeranian University of Technology, Faculty of Civil Engineering and Architecture, \\ al. Piastów 50, Szczecin, Poland
}

\begin{abstract}
There are several calculation models for estimation of shrinkage in concrete. The most popular ones are: ACI-209R-92 method, Bažant-Baweja model (B3), Gardner'a-Lockman'a model (GL 2000), CEB-FIP (CEB MC90-99), Spanish model (EHE), EuroCode method (EC-2) from 2004 and Tazawa-Miyazawa model (JSCE). Majority of aforementioned models do not include the deformation caused by the autogenous shrinkage. The methods assume the total deformation as a result of drying shrinkage action. Additionally, a non-standard method was proposed by Jonasson and Hedlund. However it only is used to determine the autogenous shrinkage of High-Performance Concretes (HPC). TazawaMiyazawa model and Jonasson-Hedlund method are based on the proportions and material properties such as water/cement ratio, water/binder ratio, type of the cement, or start of setting time. In contrary, the CEB MC90-99 and EC-2 models correlate the autogenous shrinkage with the overall compressive strength of concrete. The article presents the analysis of various calculation models in comparison to actual measurements. The autogenous shrinkage was measured in four cement composites starting at casting up till 28 days of curing.
\end{abstract}

\section{Introduction}

The first measurement of autogenous deformations have been made by La Chatelier in 1900. The researcher has described in his research a phenomenon occurring from the beginning of setting process up till later stages of cement hardening [1]. The research by Davis [2] and Lyman [3] in the 1940s have showed that a 5 year old concretes exhibit an autogenous deformation of $50-100 \mu \mathrm{m} / \mathrm{m}$. Compared to thermal deformation and drying shrinkage the value of autogenous shrinkage appeared rather insignificant. Further studies of autogenous effects were omitted [4]. According to others researchers it can be assumed, that the total deformation of traditional concrete after 28 days is about $500 \mathrm{um} / \mathrm{m}$, which of

\footnotetext{
*Corresponding author: adam.zielinski@zut.edu.pl
} 
autogenous shrinkage is about $80 \mathrm{um} / \mathrm{m}$. On the other hand we have high-performance concrete, where autogenous shrinkage can reach over $300 \mathrm{um} / \mathrm{m}$ when drying shrinkage is about $150 \mathrm{um} / \mathrm{m}$. Total shrinkage of HPC is lower in comparison to traditional concrete. These analysis and shrinkage values are generalized and it should be analyzed due to composition of cement composites.

The breakthrough in the approach to autogenous shrinkage appeared after 1980s. The implementation of new generation of concretes and development of concrete technology created new issues that had to be addressed. Invention of chemical admixtures which reduce the water/cement ratio and implementation of reactive mineral additives, including silica fume launched the rise of High-Performance Concretes (HPC). Several factors have influenced the increase of the general value of shrinkage in concretes. For starters, use of reactive additives produced more compact cement matrix. With higher amounts of binder there was a noticeable increase of the chemical shrinkage, drying effect and autogenous shrinkage [5].

Dynamic implementation of HPC in real life has posed a necessity for scientific studies on this new technology. In mid-80s, despite strict control over water loss and reduction of temperature changes during curing there was a visible increase of cracking in constructed elements. Laboratory tests showed that rapidly developing autogenous deformations are the cause of this phenomenon [6].

There are numerous studies in the subject of autogenous deformations. Several methods were proposed to reduce the negative effect of autogenous shrinkage. Those include use of Shrinkage Reducing Admixtures (SRA), internal curing [7] or dispersed micro-reinforcement.

Several calculation models have been proposed that utilize the material proportions and compressive strength to predict the value of shrinkage.

In the paper the authors try to analyze the existing models and investigate the correctness of calculated estimations based on laboratory tests. The conducted tests proved some shortages in the models. It is necessary to include the amount of aggregate as a factor influencing autogenous shrinkage.

\section{Mixture proportions and specimen}

The study was performed on two High-Performance Self Consolidating Concretes with coarse, natural aggregate $(\mathrm{C}-3, \mathrm{C}-4)$ and two cement composites with fine aggregate $(\mathrm{C}-1$, $\mathrm{C}-2)$. The water/cement ratio was set to 0.28 (C-2, C-3), 0.34 (C-4) and 0.42 (C-1). $\mathrm{C}-1$ and $\mathrm{C}-2$ mixes contained high amount of cement and reduced amount of aggregate.

All of the mixes were made using Rapid Portland Cement CEM I 42.5 R, fly ash, silica fume and superplasticizer. The ratio of mineral additives to cement was constant. To obtain proper workability and self-consolidating properties the superplasticizer was dosed between $0.5 \%$ to $2.5 \%$ of cement mass. The mix design are visible in Table 1 .

The autogenous deformation was measured on three $150 \times 35 \times 1150 \mathrm{~mm}$ samples. Displacement was measured from the casting time up till 28 days with $500 \mathrm{~s}$ intervals.

Compressive strength for the composites was different. After 28 days, the compressive strength on $10 \times 10 \times 10 \mathrm{~cm}$ specimens was: C-1: $\mathrm{f}_{\mathrm{cm}}=71 \mathrm{MPa}$; $-2: \mathrm{f}_{\mathrm{cm}}=102,9 \mathrm{MPa}$; C-3: $\mathrm{f}_{\mathrm{cm}}=100,5 \mathrm{MPa}$ and $\mathrm{C}-4: \mathrm{f}_{\mathrm{cm}}=99,6 \mathrm{MPa}$. 
Table 1. Mix design.

\begin{tabular}{|c|c|c|c|c|c|c|c|c|}
\hline \multirow{3}{*}{$\stackrel{\ltimes}{\Sigma}$} & \multirow{3}{*}{$\frac{0}{3}$} & \multirow{3}{*}{ 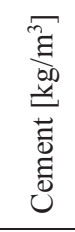 } & \multirow{2}{*}{\multicolumn{2}{|c|}{ 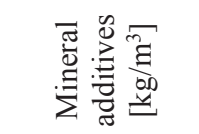 }} & \multirow{3}{*}{ 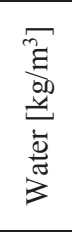 } & \multirow{3}{*}{ 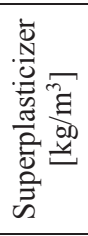 } & \multirow{2}{*}{\multicolumn{2}{|c|}{$\begin{array}{c}\text { Aggregate } \\
{\left[\mathrm{kg} / \mathrm{m}^{3}\right]} \\
\text { Natural }\end{array}$}} \\
\hline & & & & & & & & \\
\hline & & & $\frac{\lambda}{\Delta} \vec{y}$ & 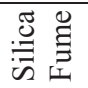 & & & $0 \div 2$ & $2 \div 8$ \\
\hline C-1 & 0,42 & 725 & 116 & 61 & 305 & 3,45 & 1004 & - \\
\hline C-2 & 0,28 & 794 & 127 & 67 & 222 & 18,0 & 1100 & - \\
\hline C-3 & 0,28 & 458 & 73,3 & 39 & 128 & 12 & 636 & 1092 \\
\hline C-4 & 0,34 & 450 & 72 & 38 & 155 & 8,0 & 624 & 1072 \\
\hline
\end{tabular}

\section{Calculation model characteristics}

Four models were chosen for analysis, two based on component proportion and two based on compressive strength of concrete (the algorithms of all analyzed models are in Table 2).

Table 2. Autogenous shrinkage calculation models.

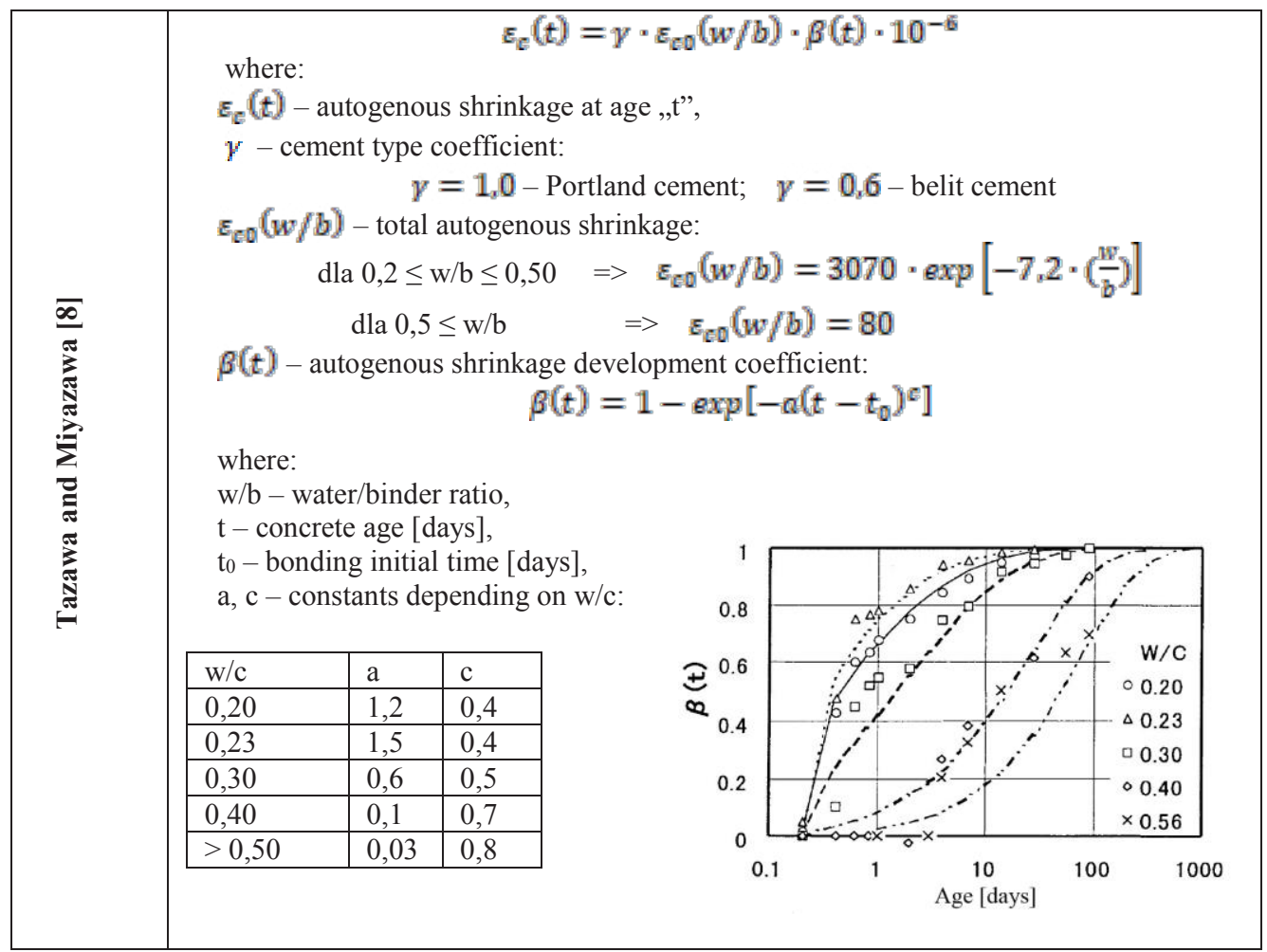




\begin{tabular}{|c|c|}
\hline 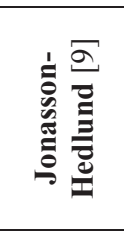 & $\begin{array}{l}\qquad \varepsilon_{a s}(t)=[-0,65+1,3(w / b)] \cdot 10^{-3} \times \exp \left[-\left(\frac{5}{t-t_{\text {start }}}\right)^{0,3]}\right] \\
\text { where: } \\
\varepsilon_{\text {as }}(t) \text { - autogenous shrinkage at age ,t", } \\
t_{\text {start }}-\text { starting age of autogenous shrinkage development (after 1 day) }\end{array}$ \\
\hline 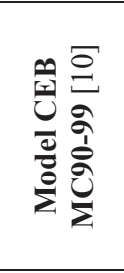 & $\begin{array}{l}\qquad \varepsilon_{c a s}(t)=-\alpha_{a s}\left(\frac{f_{c m 2 g} / 10}{6+f_{c m 2 s} / 10}\right)^{2,5} \cdot[1-\exp (-0,2 \sqrt{t})] \\
\text { where: } \\
f_{c m 28}-\text { average compressive strength of concrete on day } 28 \text { (cylinder), [MPa], } \\
\alpha_{a s}-\text { coefficient describing the type of cement: } \\
\alpha_{a s}=800 \text { - CEM „L"; } \alpha_{a s}=700-\mathrm{CEM}, \mathrm{N} " /, \mathrm{R} " ; \alpha_{a s}=600-\mathrm{CEM}, \mathrm{R} "\end{array}$ \\
\hline 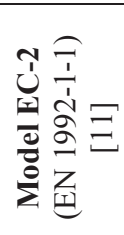 & $\begin{array}{l}\qquad \varepsilon_{c a}(t)=\beta_{a g}(t) \cdot \varepsilon_{c a}(\infty) \\
\text { where: } \\
\varepsilon_{c a}(\infty) \text { - total autogenous shrinkage: } \quad \varepsilon_{c a}(\infty)=2,5 \cdot\left(f_{c k}-10\right) \cdot 10^{-6} \\
\beta_{a s}(t) \text { - shrinkage development rate coefficient: } \\
\beta_{a s}(t)=1-e^{(-0,2 \sqrt{t})}\end{array}$ \\
\hline
\end{tabular}

The Jonasson-Handlund method [9] that takes into account water/binder ratio can be only used for concretes with $w / b \leq 0,4$ and compressive strength of fcm $\geq 80 \mathrm{MPa}$. TazawaMiyazawa model can be used for concretes with w/b between $0,2 \leq \mathrm{w} / \mathrm{b} \leq 0,56$, standard aggregate volume and surrounding temperature of $\mathrm{t}=20-60^{\circ} \mathrm{C}$.

The CEB MC90-99 and EC 2 models assume that the autogenous shrinkage depends mainly on concrete's compressive strength after 28 days.

\section{Analysis of effectiveness of models for evaluation of autogenous shrinkage}

Every empirical model determined the values of autogenous shrinkage in a set period. Figures 1 and 2 show the correlation of calculated values with actual measurement of autogenous shrinkage in $\mathrm{C}-1$ and $\mathrm{C}-2$ concretes.

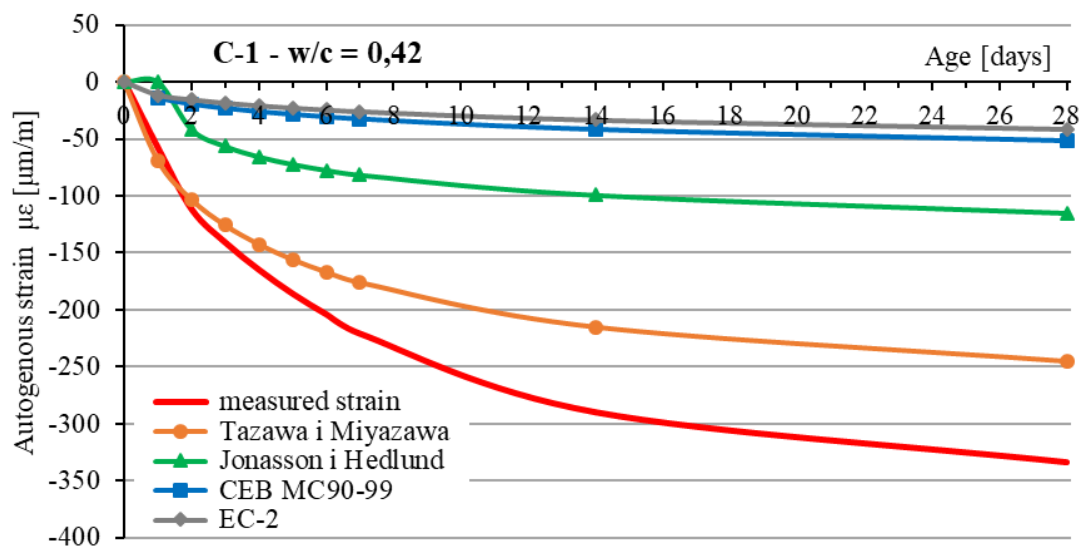

Fig. 1. Comparison of measured autogenous shrinkage of C-1 composite with calculated values. 


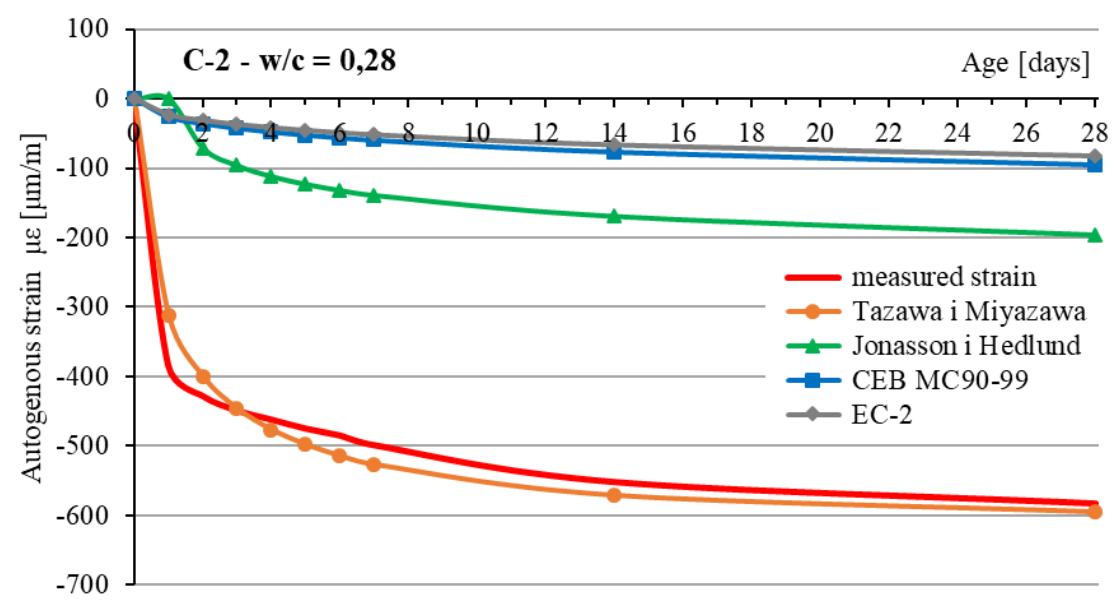

Fig. 2. Comparison of measured autogenous shrinkage of C-2 composite with calculated values.

Most approximate results were acquired by Tazawa-Miyazawa model. The comparison was most compatible for $\mathrm{C}-2$ concrete with the lowest w/c ratio 0.28 and highest cement content. At higher water/cement ratio the model prognoses lower values of autogenous shrinkage. Model proposed by Jonnason and Hedlund understates the autogenous shrinkage due to its applicability only after a whole day. Compressive strength based models of CEB MC90-99 (CEB-FIP model) and EC-2 strongly understate the values of autogenous shrinkage. In case of the $\mathrm{C}-2$ composite with fine aggregate, the calculated value constitutes to only $20 \%$ of measured value.

Figure 3 and 4 show the correlation of calculation models with measures of autogenous shrinkage in C-3 and C-4 composites. Figure 5 shows the comparison between model for all studied mixes.

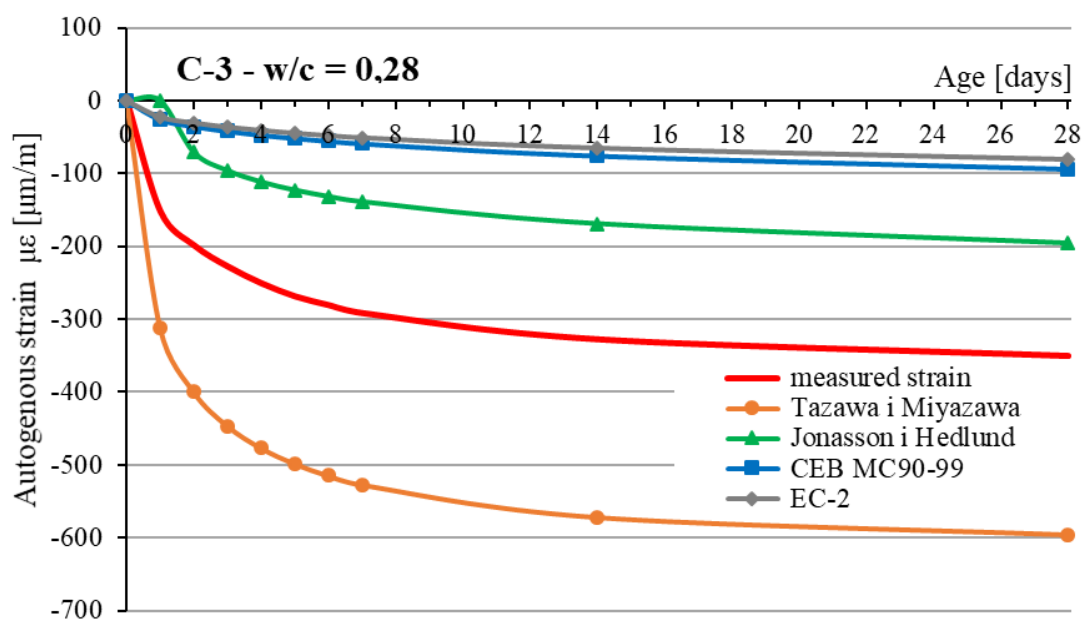

Fig. 3. Comparison of measured autogenous shrinkage of C-3 composite with calculated values. 


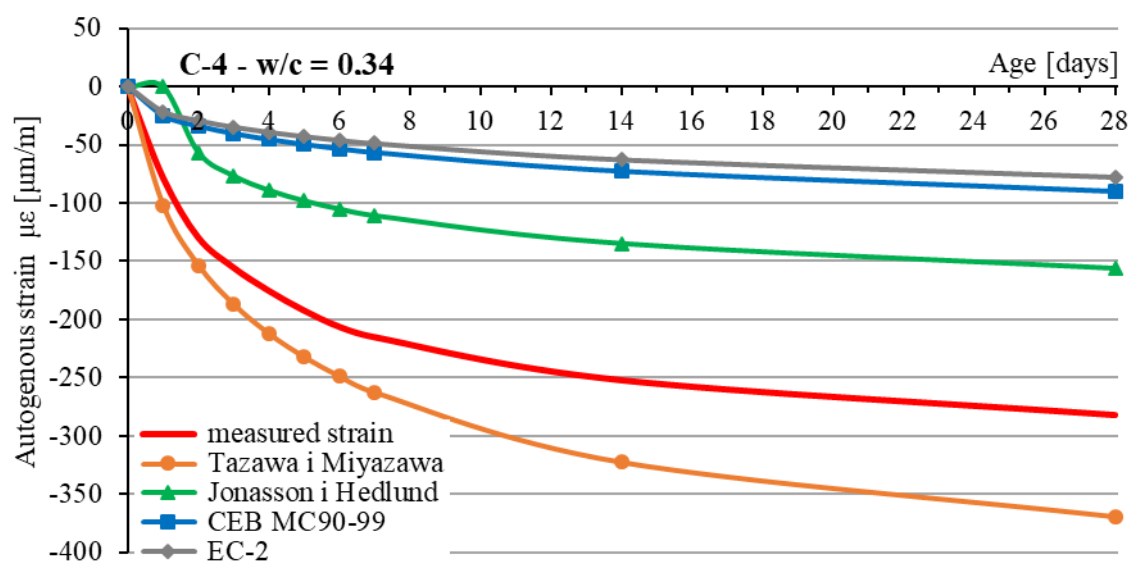

Fig. 4. Comparison of measured autogenous shrinkage of $\mathrm{C}-4$ with calculated values.

The Tazawa-Miyazawa model does not account the amount and type of aggregate. This is visible considering the values calculated for C-2 and C-3 composites. The calculations for both mixes resulted in exact values of autogenous shrinkage. However, increasing the amount of aggregate reduced the overall autogenous shrinkage in C-3 composite.

The Jonnason-Hedlund model understates the values of autogenous shrinkage for C-2 and C-3. The model takes into account only shrinkage that occurs after a day. For C-2 and C-3 composites, the values of measured shrinkage in the first $24 \mathrm{~h}$ reached $50 \%$ of overall value, proving the method to be non-appropriable. Only after adding the values from the first $24 \mathrm{~h}$, the model provides a correct representation of autogenous shrinkage.

The increase of the w/c ratio while retaining constant aggregate volume (C-3 and C-4) causes reduction of autogenous shrinkage and increase the correlation between CEB MC and EC-2 and measured values. With a lowered w/c ratio of 0.34 the compressive strength models understate the shrinkage almost three-folds.

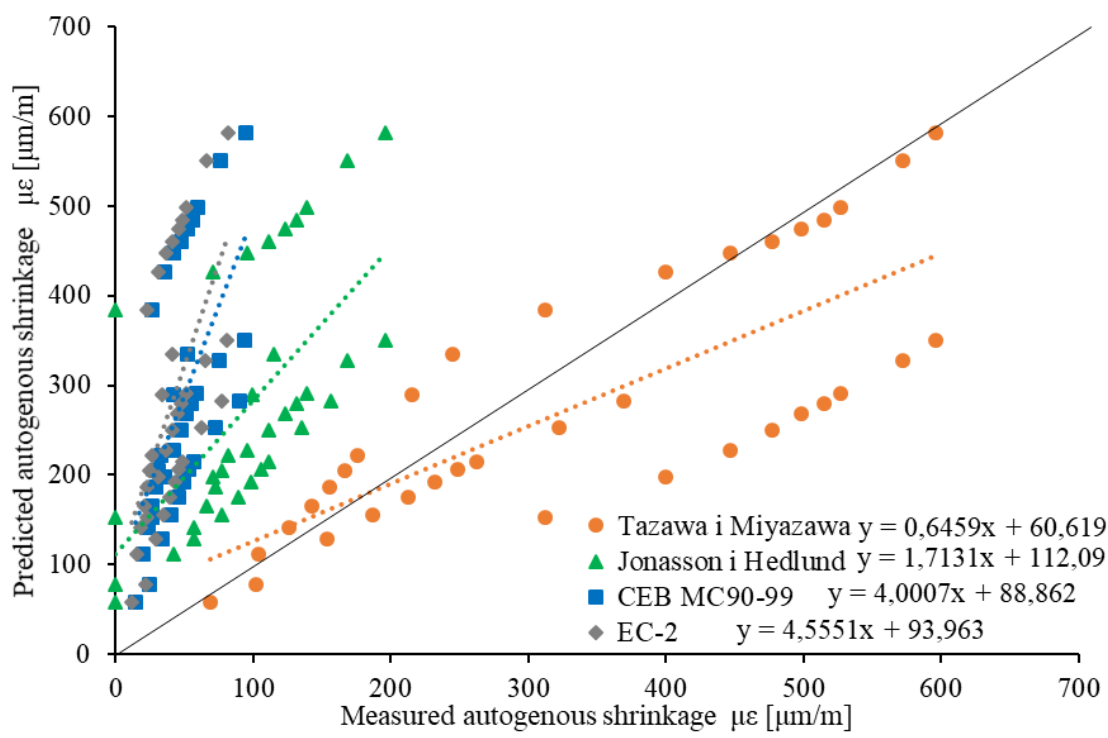

Fig. 5. Correlation of calculated and measured autogenous shrinkage after 1-7, 14, 28 days. 
The plots of analyzed development of autogenous shrinkage in cement composites are arithmetic mean of 3 test specimens. On 28 day, the standard deviation was: for C-1: $\sigma=$ $6,2 \mu \mathrm{m} / \mathrm{m}$, for C-2: $\sigma=30 \mu \mathrm{m} / \mathrm{m}$, for C-3: $\sigma=15 \mu \mathrm{m} / \mathrm{m}$, for C-4: $\sigma=12 \mu \mathrm{m} / \mathrm{m}$. In this situation, we can observe a large convergence of the registered autogenous strain on each of the three individual concrete specimens.

The increase of the w/c ratio above 0.34 increases the models-to-measurement correlation. However, the Tazaway-Miyazawa model overstates the values while other model understate them. In case of the $\mathrm{C}-1 \mathrm{mix}$, with the highest $\mathrm{w} / \mathrm{c}$ ratio, high cement content and lowered volume of aggregate, rapidly developing shrinkage was understated by all models.

Highest models-to-measurement correlation was acquired for C-2 composite with lowest $\mathrm{w} / \mathrm{c}$. The cement composite $\mathrm{C}-2$ has obtained the highest autogenous shrinkage, which was about $580 \mathrm{um} / \mathrm{m}$ after 28 day. Such a large strain was imposed by: low water/cement ratio, high content of cement and silica fume, lack of thick non-deformation natural aggregate.

The presented analysis shows that the value of autogenous shrinkage evaluated by CEM-MC and EC 2 methods is significantly understated. This is concurring with other studies [8]. Long et al. noticed that concretes with higher w/c ratio, thus lower autogenous shrinkage exhibit higher correlation with calculation models, especially the Japanese model [12].

\section{Conclusions}

Following conclusions can be drawn:

- The highest correlation was acquired for Tazawa-Miyazawa model. It was particularly precise for concretes with lower w/c and high content of cement. The model does not account for amount and type of aggregate;

- The Jonnason-Hedlund model strongly understates the autogenous shrinkage, due to being applied only after first 24 hours;

- The CEB MC90-99 and EC-2 models understate the actual value of autogenous shrinkage the lower the water/cement ratio;

- None of the models takes into account the influence of cement/aggregate ratio on predicted values of autogenous shrinkage.

\section{References}

1. Le Chatelier H., Sur les changements de volume qui accompagnent le durcissement des ciments, Bulletin de la Société pour l'Encouragement Industriel Nationale, 5 (1900)

2. Davis H.E. (ed.). Autogenous volume change of concrete, proc. ASTM 40, 1103-1110 (1940)

3. Lyman C.G. Growth and movement in Portland cement concrete, Oxfort University Press (1934)

4. Jensen O.M. Hansen P.F., Cement and Concrete Research, 31(12), 1859-1865 (2001)

5. Aïtcin P.C. High-performance concrete, E \& FN SPON (2007)

6. Palliere A.M., Buil M., Serrano J.J. Materials Science to Construction Materials Engineering, 3, 990-997 (1987) 
7. Kaszynska M., Zielinski A., Procedia Engineering, 108, 608-615 (2015)

8. Tazawa E., Miyazawa S. Concrete Library of JSCE, 31, 371-380 (1997)

9. Jonasson J.E., Hedlund H. (ed.). An engineering model for creep and shrinkage in high performance concrete, RILEM Proceedings PRO 17, Shrinkage of Concete, 507-529 (2000)

10. ACI 209R-92: Prediction of Creep, Shrinkage, and Temperature Effects in Concrete Structures

11. EN 1992-1-1:2008 Eurocode 2: Design of concrete structures - Part 1- General rules and rules for buildings

12. Long W.J., Khayat K.H., Xing F. The Open Civil Engineering Journal, 5, pp.116-123 (2011) 